\title{
Efeitos da invasão por Panicum maximum Jacq. e do seu controle manual sobre a regeneração de plantas lenhosas no sub-bosque de um reflorestamento
}

\section{Impacts of Panicum maximum Jacq. invasion and its manual weeding on the wood plant regeneration in the understory of a restoration site}

\author{
Maurício Cruz Mantoani ${ }^{1}$; Gabriela Ribeiro de Andradeㄹ; Alba Lúcia Cavalheiro후 \\ José Marcelo Domingues Torezan ${ }^{1,2}$
}

\begin{abstract}
Resumo
Responsáveis por perdas anuais consideráveis na biodiversidade dos ecossistemas naturais, as espécies exóticas invasoras causam sérios problemas à conservação, levando muitas espécies à extinção local. Este estudo analisou o efeito da cobertura de capim-colonião (Panicum maximum Jacq.) no sub-bosque de um reflorestamento dominado há mais de 17 anos por essa gramínea exótica invasora, pois resultados preliminares apontam-na como barreira para o estabelecimento de espécies nativas. Neste estudo, foram implantadas 20 parcelas de $5 \mathrm{~m} \times 5 \mathrm{~m}\left(25 \mathrm{~m}^{2}\right)$ distribuídas em dois tratamentos, controle e remoção de capim-colonião, para se avaliar o impacto da capina manual sobre o sub-bosque num período de 90 dias. Dados acerca da cobertura de P. maximum e a porcentagem de abertura do dossel foram coletados. A cobertura de capim-colonião teve correlação negativa com a abundância de plantas, com a riqueza de espécies e com a abundância de espécies arbóreas. A abertura do dossel influenciou negativamente a riqueza de espécies, a abundância e a riqueza de espécies arbóreas, mas não teve correlação com a cobertura de $P$. maximum. Após a remoção da gramínea, tanto a abundância de regenerantes quanto a riqueza de espécies não apresentaram diferenças significativas entre os tratamentos, logo a capina manual não causou impacto negativo em curto prazo na regeneração do sub-bosque, já que poucas plantas foram acidentalmente arrancadas. Porém, um impacto positivo é esperado somente após um período maior de observação, após sucessivas remoções da herbácea invasora e aumento de chance de colonização da área por regenerantes.
\end{abstract}

Palavras-chave: Abertura do dossel. Cobertura de herbáceas. Competição. Espécies exóticas. Restauração ecológica.

\footnotetext{
${ }^{1}$ Laboratório de Biodiversidade e Restauração de Ecossistemas (LABRE), Universidade Estadual de Londrina.

2 Autor correspondente. Caixa Postal 6001, CCB/BAV, 96.051-990 Londrina-PR. E-mail: torezan@uel.br.
} 


\begin{abstract}
Responsible for considerable annual losses of biodiversity in natural ecosystems, invasive alien species cause important conservation problems, leading native species to local extinction. This study examined the relationship among the coverage of Guinea-grass (Panicum maximum Jacq.), its manual weeding and the woody plant diversity of a restoration site. The site is a reforestation created using native species but due to spacing and species composition grass still dominates its understory more than 17 years after. Preliminary results showed that it is a barrier to the establishment of native species. In this study, we established 20 plots of $5 \mathrm{~m} \times 5 \mathrm{~m}$ divided into two treatments, control and removal of $P$. maximum, to investigate the impact of manual weeding on the understory in a period of 90 days. Grass cover and canopy openness were also recorded. The grass cover had negative correlation with the abundance of plants, with the species richness and abundance of tree species. Canopy openness had a negative influence on the species richness, on abundance and richness of tree species, but not showed correlation with P. maximum. After grass removal, both abundance of seedling and species richness had no significant differences, so the manual weeding did not cause a negative impact in short time on the regeneration of the understory due to accidental native plant uprooting. However, a positive impact is expected only after a longer period of observation, after successive removals of invasive herbaceous and increased chance of colonization of the area by regenerating seedlings.
\end{abstract}

Keywords: Canopy openness. Herb cover. Competition. Alien species. Ecological restoration.

\section{Introdução}

Responsáveis por grandes perdas na diversidade biológica de ecossistemas naturais, as espécies exóticas invasoras podem levar ao desaparecimento das espécies nativas por competição e alteração das características do ambiente em que se instalaram, modificando ciclos biogeoquímicos, microclima e reciclagem dos nutrientes (MACK et al., 2000). Assim, após a instalação da espécie invasora e conseqüente dominação do ambiente, apenas algumas medidas, como o controle da espécie indesejada, podem diminuir os impactos negativos causados no ecossistema (WITTENBERG; COCK, 2001).

A regeneração natural do sub-bosque de fragmentos naturais, reflorestamentos ou áreas degradadas, e conseqüente sucessão ecológica, possui várias barreiras para sua ocorrência como competição contra gramíneas, baixa fertilidade do solo, predação e dispersão de propágulos (PARROTTA; TURNBULL; JONES, 1997; HOLL et al., 2000; ZIMMERMAN; PASCARELLA; AIDE, 2000). Outros fatores como o microclima, a radiação solar que chega ao estrato inferior, a cobertura de dossel, dinâmica da comunidade do dossel (morte e queda de indivíduos, florada e frutificação) e espaço físico são imprescindíveis para a colonização do sub-bosque (DENSLOW, 1987; VANDENBERGHE et al., 2006; CAMPANELLO et al., 2007; MONTTI et al., 2011). Assim, as árvores que compõem o estrato superior afetam diretamente esses outros fatores e, conseqüentemente, a densidade de plântulas e a riqueza de espécies regenerantes do sub-bosque (PARROTTA, 1995).

Como forma de manejo e proteção de áreas afetadas e invadidas por espécies exóticas, vários estudos apontam que a remoção das mesmas pode melhorar a abundância e a riqueza de espécies nativas nos locais invadidos em longo prazo (acima de seis meses e menos de dez anos), por aumentar as taxas de germinação e sobrevivência de plântulas (HOLL et al., 2000; POSADA; AIDE; CAVELIER, 2000; ZIMMERMAN; PASCARELLA; AIDE, 2000; DUNCAN; CHAPMAN, 2003; VANDENBERGHE etal., 2006; CAMPANELLO et al., 2007; VIDRA; SHEAR; 
STUCKY, 2007). Contudo, a remoção de exóticas, em especial gramíneas, pode inicialmente diminuir o estabelecimento de indivíduos regenerantes, caso a mesma seja muito drástica, como o uso de tratores de corte rente ao chão (SAMPAIO; HOLL; SCARIOT, 2007) ou mesmo a remoção de outras formas de vegetação (i.e., arbustos) que poderiam facilitar a regeneração local (CHAPMAN et al., 2002; DUNCAN; CHAPMAN, 2003).

Pivello (2008) aponta a necessidade de estudos de combate às gramíneas africanas no país utilizando diferentes técnicas de controle (capina manual, capina mecânica, aplicação de herbicida, controle biológico) e de arranjo paisagístico (plantio de indivíduos de espécies de crescimento rápido para sombreamento e espaçamento utilizado nos reflorestamentos). Justifica o que foi dito o fato de a maior parte das pesquisas desenvolvidas com essas espécies terem a finalidade de aumento de produtividade: elas são utilizadas em larga escala para alimentação de gado e outras criações, e não objetivam aspectos de conservação e de manejo ecológico de áreas degradadas.

Dentre as gramíneas exóticas invasoras, destaca-se o capim-colonião (Panicum maximum Jacq.). Perene e heliófita, essa gramínea é oriunda da África e foi introduzida no Brasil para se criar pastagens para o gado na época da colonização (SILVA, 1968). Forma touceiras resistentes e propaga-se de forma vegetativa e por dispersão de sementes pelo vento e por aves granívoras (SILVA, 1969), sendo considerada uma espécie invasora agressiva que, além de reservas naturais, prejudica certas culturas como a da cana-de-açúcar (KISSMANN, 1997). É verificada sua invasão e permanência no sub-bosque de áreas com presença elevada de espécies decíduas, especialmente em área de restauração (SOUZA; BATISTA, 2004).

Dessa maneira, este estudo teve o objetivo de avaliar o impacto inicial da remoção do capimcolonião (Panicum maximum Jacq.) sobre o sub- bosque de uma área de reflorestamento dominada por essa gramínea, tendo por hipótese que a capina manual com o uso de enxadas não causa um impacto negativo em curto prazo (90 dias) para a regeneração local, por não arrancar acidentalmente muitos indivíduos regenerantes. Esse reflorestamento se localiza ao lado de um fragmento de floresta madura em bom estado de conservação e não foi criado com fins de restauração ecológica, mas após 17 anos, havia a expectativa de que seu subbosque estivesse dominado por espécies nativas (BARBOSA, 2006) devido à proximidade com o fragmento florestal.

\section{Material e Métodos}

\section{Área de estudo}

O trabalho foi conduzido no Parque Estadual "Mata dos Godoy" (2327’S, 511'ㅇ, PEMG), uma floresta estacional semidecidual, em Londrina, norte do estado do Paraná, Brasil. De clima subtropical úmido do tipo Cfa, a região do $\mathrm{PEMG}$ possui verões quentes e chuvosos, e invernos pouco rigorosos com baixa incidência de geadas; apresenta temperatura média anual de $21^{\circ} \mathrm{C}$, umidade relativa do ar em torno de $75 \%$ e média anual de precipitação entre 1450 e 1600 mm (VICENTE, 2006). Os solos pertencem a categoria de solo do tipo Latossolo Roxo Eutroférrico e Nitossolo Vermelho Eutroférrico, derivados de antigas erupções vulcânicas que derramaram basalto na região (VICENTE, 2006; nomenclatura atualizada de acordo com EMPRESA BRASILEIRA DE PESQUISA AGROPECUÁRIA, 1999).

O PEMG possui uma área de reflorestamento conhecida como Projeto Madeira, situada em altitude média de $610 \mathrm{~m}$ a.n.m. e implantada em 1990 com o propósito de se testar o potencial madeireiro de cinco espécies nativas, Colubrina glandulosa Perkins (Rhamnaceae; sobrasil), Cordia trichotoma (Vell.) Arrab. ex Steud. (Boraginaceae; 
louro-pardo), Parapiptadenia rigida (Benth.) Brenan (Fabaceae - Mimosoideae; gurucaia), Peltophorum dubium (Spreng.) Taub. (Fabaceae - Caesalpinioideae; canafístula), e Tabebuia impetiginosa (Mart.) Standl. (Bignoniaceae; ipêroxo) (VICENTE, 2006). Contudo, por suas características estruturais (espaçamento $3 \mathrm{~m} \times 3 \mathrm{~m}$ ), unidas à biologia das espécies plantadas (todas são decíduas e autocóricas ou anemocóricas), o Projeto Madeira, mesmo estando adjacente a um fragmento de floresta bem conservado, possui o sub-bosque dominado por capim-colonião, uma gramínea exótica invasora, há mais de 17 anos (Panicum maximum Jacq.) (BARBOSA, 2006).

\section{Desenho Experimental}

Foram implantadas 20 parcelas de $5 \mathrm{~m} \times 5 \mathrm{~m}$ $\left(25 \mathrm{~m}^{2}\right)$, totalizando $500 \mathrm{~m}^{2}$, com cobertura de P. maximum (tratada neste trabalho pela sigla “CH”) mínima de 75\% (estimada visualmente, ver método abaixo), distribuídas por sorteio em dois tratamentos: controle e remoção de capim-colonião (capina manual), com dez parcelas cada. A técnica de capina manual (feita com auxílio de enxadas, por três pessoas, em dois dias de trabalho) foi empregada pela impossibilidade de usar tratamento químico, dado que a área de estudo é uma unidade de conservação, bem como para evitar danos mais severos à regeneração de espécies nativas, caso fossem empregadas roçadeiras costais ou movidas a trator.

A área capinada em cada parcela do tratamento excedeu os limites da parcela em $1 \mathrm{~m}$. Todas as touceiras de capim colonião foram arrancadas e removidas da parcela.

\section{Coleta dos dados}

Em todas as parcelas foi realizado um monitoramento, que consistiu no inventário prévio (Fevereiro de 2008) e posterior (90 dias após Junho de 2008) à remoção de $P$. maximum (março de 2008). Com exceção das árvores plantadas no reflorestamento, todos os indivíduos de espécies lenhosas com $10 \mathrm{~cm}$ ou mais de altura foram incluídos no estudo, sendo marcados com placas de identificação.

Foram estimadas a riqueza e a abundância total de espécies lenhosas. Todas as espécies amostradas foram classificadas de acordo com seus hábitos vegetativos (arbóreas, arbustivas e lianas). As espécies que não puderam ser identificadas no campo foram coletadas e herborizadas para identificação em herbário, e os nomes das espécies seguiram o padrão de nomenclatura do Missouri Botanical Garden (www.tropicos.org).

A cobertura de capim-colonião foi estimada subdividindo-se as parcelas em quatro subparcelas, realizando-se a estimativa visual em intervalos de $5 \%$, com posterior soma/média das proporções relativas das quatro sub-parcelas. Para avaliar o nível de cobertura e a descontinuidade do dossel, foram feitas fotos hemisféricas (com lente "olho de peixe" ou de distância focal de $8 \mathrm{~mm}$ ) tiradas a $1 \mathrm{~m}$ do nível do solo e analisadas com o software Gap Light Analyzer - GLA v. 2.0 (FRAZER; CANHAM; LERTZMAN, 1999), as quais possibilitaram avaliar a porcentagem de abertura de dossel (tratada neste trabalho pela sigla "AD") das parcelas implantadas antes (Fevereiro de 2008 - verão) e depois (Junho de 2008 - Inverno) da capina manual (Março de 2008).

\section{Análise dos Dados}

As médias de riqueza e a abundância total de espécies, riqueza e abundância de espécies arbóreas, arbustivas e lianas foram calculadas para cada grupo de parcelas (controle e remoção) e comparadas entre si com o uso de teste " $t$ " para amostras independentes. Para avaliar os efeitos da cobertura florestal e da cobertura de capimcolonião sobre a estrutura e a diversidade da regeneração, foi empregada análise de regressão 
e ajuste dos dados a um modelo linear. A análise de correlação entre a $\mathrm{AD}$ e a $\mathrm{CH}$ não foi realizada no período posterior à capina manual das parcelas, uma vez que a cobertura da gramínea no bloco de remoção foi reduzida a zero.

Por não atenderem as premissas de distribuição normal (teste de Shapiro-Wilk) e homocedasticidade das variâncias (teste de Levene) para se adequarem aos testes paramétricos, os dados de $\mathrm{AD}$ e de $\mathrm{CH}$ foram transformados em arco-seno da proporção, enquanto que os dados de abundâncias foram transformas em $\log (\mathrm{x}+1)$ e os de riquezas em raiz quadrada de $(x+0,5)$. Após tais transformações, todos os dados foram novamente analisados e tiveram constatadas suas distribuições normais e homogeneidade das variâncias.
Todas as análises foram feitas no software estatístico R v. 2.14.0 (R FOUNDATION FOR STATISTICAL COMPUTING, 2008), adotandose $\alpha=0,05$.

\section{Resultados}

Os tratamentos não apresentaram diferenças significativas quanto $\mathrm{CH}$, com média de $84 \%$ no controle e média de $83,5 \%$ na remoção, tampouco para a AD, com médias de $19,11 \%$ e $19,98 \%$ para o grupo de controle e remoção, respectivamente. Antes da intervenção, os tratamentos não apresentaram diferenças significativas para as variáveis de abundância e riqueza total de espécies, assim como para todos os parâmetros analisados (Tabela 1).

Tabela 1 - Abundância $(\mathrm{N})$ e riqueza $(\mathrm{S})$ de espécies lenhosas, antes e após a remoção de herbáceas exóticas invasoras (Panicum maximum Jacq.) em um reflorestamento de 17 anos junto ao Parque Estadual "Mata dos Godoy", Londrina-PR. *Não há diferenças significativas entre os valores apresentados abaixo.

\begin{tabular}{lcccc}
\hline Variáveis & \multicolumn{2}{c}{ Controle } & \multicolumn{2}{c}{ Remoção } \\
& Antes & Depois & Antes & Depois \\
\hline Abundância (N) & 523 & 615 & 541 & 685 \\
Riqueza total (S) & 65 & 62 & 61 & 62 \\
N Arbóreas & 348 & 406 & 352 & 418 \\
N Arbustivas & 38 & 48 & 28 & 36 \\
N Lianas & 136 & 158 & 157 & 226 \\
S Arbóreas & 85 & 93 & 75 & 88 \\
S Arbustivas & 21 & 19 & 17 & 21 \\
S Lianas & 50 & 56 & 62 & 53 \\
\hline
\end{tabular}

Fonte: Autores.

Nas 20 parcelas estudadas, foram listadas 95 morfo-espécies, das quais 86 foram identificadas como pertencentes a 39 famílias (68 foram identificadas até o nível específico, dez até gênero, oito até família e nove não foram identificadas) (Tabela 2). 
Tabela 2 - Lista de espécies lenhosas amostradas em 20 parcelas no sub-bosque do Projeto Madeira, Parque Estadual Mata dos Godoy, Londrina-PR. Dados de abundância total de espécies antes e depois da capina manual de herbáceas exóticas invasoras (Panicum maximum Jacq.).

\begin{tabular}{|c|c|c|c|c|c|c|}
\hline \multirow[t]{2}{*}{ Família } & \multirow[t]{2}{*}{ Espécie } & \multirow[t]{2}{*}{ Hábito } & \multicolumn{2}{|l|}{ Controle } & \multicolumn{2}{|l|}{ Remoção } \\
\hline & & & Antes & Depois & Antes & Depois \\
\hline Acanthaceae & Mendoncia coccinea Vell. & Liana & 0 & 0 & 3 & 0 \\
\hline \multirow[t]{2}{*}{ Anacardiaceae } & Astronium graveolens Jacq. & Arbóreo & 3 & 2 & 1 & 1 \\
\hline & Schinus terebinthifolia Raddi. & Arbóreo & 0 & 0 & 0 & 1 \\
\hline \multirow[t]{8}{*}{ Apocynaceae } & Apocynaceae 1 & Arbusto & 4 & 0 & 3 & 1 \\
\hline & Aspidosperma polyneuron Müll. Arg. & Arbóreo & 0 & 0 & 1 & 1 \\
\hline & $\begin{array}{l}\text { Condylocarpon isthmicum. } \\
\text { (Vell.) A. DC }\end{array}$ & Liana & 11 & 14 & 14 & 7 \\
\hline & Fischeria martiana Decne. & Liana & 13 & 16 & 4 & 2 \\
\hline & Forsteronia thyrsoidea (Vell.) & Liana & 0 & 0 & 2 & 3 \\
\hline & Müll. Arg. & & & & & \\
\hline & Peltastes peltatus (Vell.) Woodson & Liana & 2 & 2 & 2 & 2 \\
\hline & $\begin{array}{l}\text { Tabernaemontana catharinensis } \\
\text { A. DC. }\end{array}$ & Arbóreo & 1 & 0 & 4 & 5 \\
\hline \multirow[t]{2}{*}{ Arecaceae } & Euterpe edulis Mart. & Arbóreo & 1 & 1 & 1 & 3 \\
\hline & $\begin{array}{l}\text { Syagrus romanzoffiana (Cham.) } \\
\text { Glassman }\end{array}$ & Arbóreo & 1 & 1 & 6 & 3 \\
\hline \multirow[t]{4}{*}{ Asteraceae } & Eupatorium laevigatum Lam. & Arbusto & 1 & 1 & 6 & 7 \\
\hline & Mikania sp. 1 & Liana & 3 & 2 & 6 & 3 \\
\hline & Mikania sp. 2 & Liana & 3 & 2 & 3 & 2 \\
\hline & Vernonia polyanthes Less. & Arbusto & 3 & 1 & 1 & 2 \\
\hline \multirow[t]{4}{*}{ Bignoniaceae } & $\begin{array}{l}\text { Adenocalymma marginatum } \\
\text { (Cham.) DC. }\end{array}$ & Liana & 4 & 5 & 1 & 0 \\
\hline & $\begin{array}{l}\text { Macfadyena unguis-cati (L.) A. } \\
\text { H. Gentry }\end{array}$ & Liana & 17 & 36 & 18 & 44 \\
\hline & $\begin{array}{l}\text { Pithecoctenium crucigerum (L) } \\
\text { A. H. Gentry }\end{array}$ & Liana & 3 & 0 & 1 & 0 \\
\hline & Handroanthus impetiginosus Mattos & Arbóreo & 0 & 0 & 1 & 1 \\
\hline \multirow[t]{2}{*}{ Boraginaceae } & Cordia ecalyculata Vell. & Arbóreo & 0 & 0 & 0 & 1 \\
\hline & $\begin{array}{l}\text { Cordia trichotoma (Vell.) Arráb. } \\
\text { ex Steud. }\end{array}$ & Arbóreo & 65 & 70 & 39 & 87 \\
\hline Cannabaceae & Trema micrantha (L.) Blume & Arbóreo & 1 & 0 & 2 & 2 \\
\hline Celastraceae & Hippocratea $\mathrm{sp}$. & Liana & 0 & 0 & 1 & 1 \\
\hline \multirow[t]{2}{*}{ Cucurbitaceae } & Cayaponia sp. & Liana & 0 & 0 & 4 & 7 \\
\hline & Melothria cucumis Vell. & Liana & 1 & 0 & 0 & 0 \\
\hline Dilleniaceae & Davilla sp. & Liana & 0 & 0 & 2 & 1 \\
\hline Dioscoreaceae & Dioscoriaceae 1 & Liana & 2 & 2 & 0 & 6 \\
\hline Euphorbiaceae & Alchornea glandulosa Poepp. & Arbóreo & 2 & 3 & 3 & 3 \\
\hline
\end{tabular}


Fabaceae

(Caesalpinioideae)

Fabaceae

(Faboideae)

Fabaceae

(Mimosoideae)
Croton floribundus Spreng.

Holocalyx balansae Micheli

Lonchocarpus muehlbergianus

Hassl.

Machaerium paraguariense Hassl. Arbóreo

Machaerium stipitatum (DC.) Vogel Arbóreo

Acacia polyphylla DC.

Enterolobium contortisiliquum

(Vell.) Morong

Inga marginata Willd.

Inga striata Benth.

Parapiptadenia rigida (Benth.)

Brenan

Lauraceae

Malpighiaceae

Malvaceae

Meliaceae

Moraceae

Myrtaceae

Nyctaginaceae

Phytolaccaceae
Endlicheria paniculata (Spreng.)

J. F. Macbr.

Lauraceae 1

Lauraceae 2

Lauraceae 3

Lauraceae 4

Nectandra megapotamica

(Spreng.) Mez

Ocotea puberula (Rich.) Nees.

Ocotea sp.

Mascagnia divaricata (Kunth) Nied

Mascagnia sp.

Tetrapterys multiglandulosa A. Juss.

Heliocarpus americanus L.

Pavonia sepium A. St.-Hil.

Cedrela fissilis Vell.

Guarea kunthiana A. Juss

Melia azedarach $\mathrm{L}$.

Trichilia casaretti C. DC.

Trichilia claussenii C. DC.

Maclura tinctoria (L.) D.

Don ex Steud.

Myrtaceae 1

Bougainvillea spectabilis Willd.

Pisonia aculeata L.

Pisonia ambigua Heimerl

Gallesia integrifolia (Spreng.) Harms Arbóreo

Arbóreo

Arbóreo

Arbóreo

Arbóreo

Arbóreo

Arbóreo

Arbóreo

Arbóreo

Liana

Liana

Liana

Arbóreo

Arbusto

Arbóreo

Arbóreo

Arbóreo

Arbóreo

Arbóreo

Arbóreo

Arbóreo

Arbóreo

Arbóreo

Arbóreo

Arbóreo
Cabralea canjerana (Vell.) Mart.
Arbóreo

Arbóreo

Arbóreo

Arbóreo

15

15

Arbóreo

Arbóreo

Arbóreo

Arbóreo

$5 \quad 5$

1

2

0

0

0

0 


\begin{tabular}{|c|c|c|c|c|c|c|}
\hline \multirow[t]{5}{*}{ Piperaceae } & Piper aduncum L. & Arbusto & 7 & 13 & 0 & 3 \\
\hline & Piper amalago L. & Arbusto & 1 & 0 & 0 & 2 \\
\hline & Piper hispidum Sw. & Arbusto & 4 & 19 & 10 & 14 \\
\hline & Piper sp. & Arbusto & 9 & 1 & 0 & 0 \\
\hline & Piper umbellatum $\mathrm{L}$. & Arbusto & 1 & 0 & 0 & 0 \\
\hline Primulaceae & Rapanea umbelata (Mart.) Mez & Arbóreo & 5 & 6 & 2 & 1 \\
\hline Rhamnaceae & Gouania virgata Reissek & Liana & 10 & 10 & 19 & 41 \\
\hline \multirow[t]{3}{*}{ Rutaceae } & Citrus limon (L.) Osbeck & Arbóreo & 16 & 21 & 46 & 74 \\
\hline & Zanthoxylum caribaeum Lam. & Arbóreo & 2 & 3 & 0 & 0 \\
\hline & Zanthoxylum rhoifolium Lam. & Arbóreo & 0 & 0 & 1 & 1 \\
\hline Salicaceae & Prockia crucis P. Browne ex L. & Arbusto & 1 & 1 & 0 & 0 \\
\hline \multirow[t]{3}{*}{ Sapindaceae } & Cupania vernalis Cambess. & Arbóreo & 0 & 0 & 0 & 1 \\
\hline & Paullinia sp. & Liana & 18 & 9 & 1 & 4 \\
\hline & Serjania glabrata Kunth & Liana & 31 & 32 & 33 & 41 \\
\hline Sapotaceae & $\begin{array}{l}\text { Chrysophyllum gonocarpum } \\
\text { (Mart. \& Eichler ex Miq.) Engl. }\end{array}$ & Arbóreo & 1 & 2 & 1 & 0 \\
\hline \multirow[t]{6}{*}{ Solanaceae } & Cestrum intermedium Sendtn. & Arbóreo & 5 & 7 & 5 & 7 \\
\hline & Cestrum strigilatum Ruiz \& Pav. & Arbusto & 1 & 0 & 1 & 2 \\
\hline & Lycianthes australis (C.V. Morton) & Arbusto & 2 & 2 & 2 & 0 \\
\hline & Hunz. \& Barboza & & & & & \\
\hline & Solanaceae 1 & Arbusto & 1 & 0 & 0 & 0 \\
\hline & Solanum sp. & Arbusto & 0 & 3 & 1 & 2 \\
\hline Verbenaceae & Aloysia virgata (Ruiz \& Pav.) Pers. & Arbóreo & 2 & 2 & 0 & 0 \\
\hline \multirow[t]{11}{*}{ Violaceae } & Hybanthus bigibbosus Arbusto & & 3 & 6 & 3 & 3 \\
\hline & (A. St.-Hil.) Hassl. & & & & & \\
\hline & Indeterminada 1 & Liana & 4 & 2 & 1 & 0 \\
\hline & Indeterminada 2 & Liana & 0 & 0 & 0 & 0 \\
\hline & Indeterminada 3 & & 0 & 0 & 3 & 3 \\
\hline & Indeterminada 4 & & 0 & 0 & 0 & 1 \\
\hline & Indeterminada 5 & & 0 & 0 & 1 & 0 \\
\hline & Indeterminada 6 & & 1 & 1 & 0 & 0 \\
\hline & Indeterminada 7 & & 0 & 0 & 0 & 1 \\
\hline & Indeterminada 8 & & 0 & 1 & 0 & 0 \\
\hline & Indeterminada 9 & & 0 & 2 & 0 & 0 \\
\hline
\end{tabular}

Fonte: Autores.

Anteriormente à intervenção nas parcelas (fevereiro de 2008), a CH correlacionou-se negativamente com a abundância total de indivíduos (Figura 1), a riqueza total de espécies $\left(\beta=-2,50, \mathrm{r}^{2}\right.$ $=0,20, p=0,04)$ e a abundância de indivíduos de espécies arbóreas $\left(\beta=-1,97, r^{2}=0,38, p=0,004\right)$. Porém, não houve correlação significativa entre a $\mathrm{CH}$ e os outros parâmetros analisados (dados não apresentados). 
Figura 1 - Relação entre cobertura de Panicum maximum e abundância de indivíduos lenhosos regenerantes anteriormente à intervenção nas parcelas (dados não transformados). *O modelo linear apresentado foi feito com dados transformados (Abundância de Indivíduos $=\log (\mathrm{x}+1)$; Cobertura de P. maximum = arco-seno da proporção).

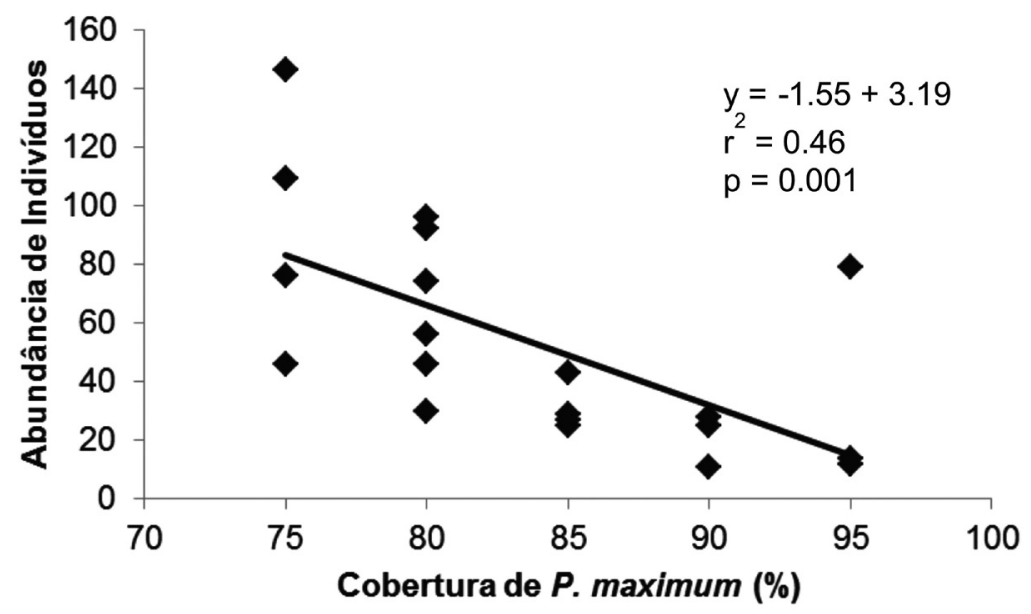

Fonte: Autores.

Ao contrário do esperado, antes da remoção da gramínea (fevereiro de 2008), a $\mathrm{AD}$ não se correlacionou com a $\mathrm{CH}\left(\beta=0,88, \mathrm{r}^{2}=0,03, \mathrm{p}=\right.$ $0,48)$, nem com a abundância total de indivíduos regenerantes $\left(\beta=-5,37, \mathrm{r}^{2}=0,19, \mathrm{p}=0,052\right)$, entretanto, ela apresentou correlação negativa com a riqueza total de espécies (Figura 2), com a abundância $\left(\beta=-8,41, r^{2}=0,24, p=0,03\right)$ e riqueza de espécies arbóreas $\left(\beta=-15,29, r^{2}=0,30, p=0,01\right)$. Para os demais parâmetros analisados também não houve correlação significativa desses com a $\mathrm{AD}$ (dados não apresentados).

Figura 2 - Relação entre abertura do dossel (\%) e riqueza de espécies lenhosas regenerantes anteriormente à intervenção nas parcelas (dados não transformados). *O modelo linear apresentado foi feito com dados transformados $($ Riqueza Total $=$ raiz quadrada de $(\mathrm{x}+0,5)$; Abertura do Dossel $=$ arco-seno da proporção $)$.

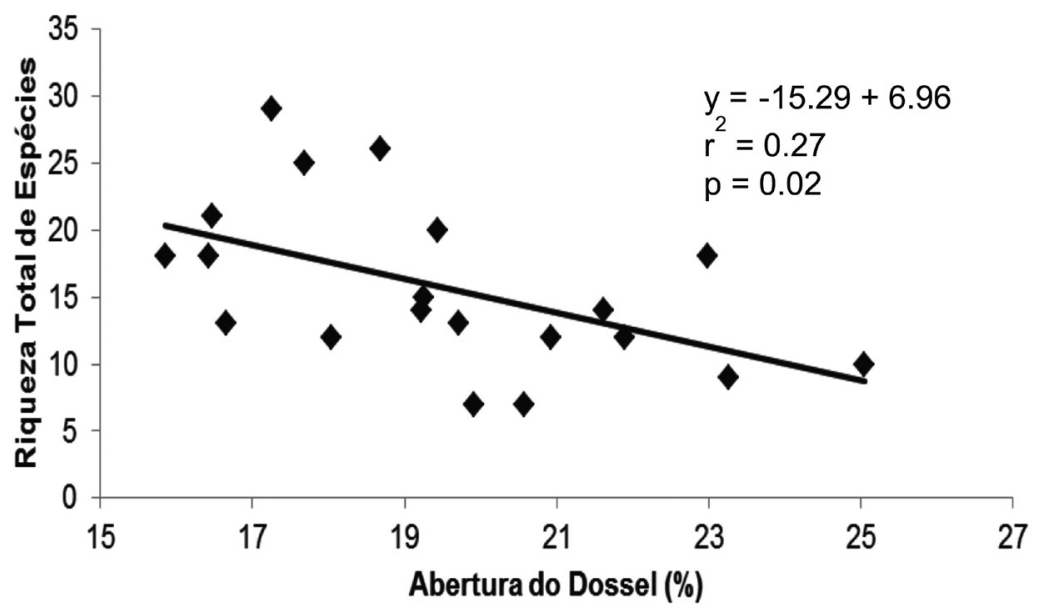

Fonte: Autores. 
Após a remoção da herbácea invasora, não houve diferenças significativas entre os tratamentos para os parâmetros de abundância total de indivíduos e riqueza total de espécies, bem como para os parâmetros de abundância e riqueza dos diferentes hábitos vegetativos (Tabela 1 e Tabela 2). Contudo, a AD do dossel afetou negativamente a abundância $\left(\beta=-7,54, r^{2}=0,27, p=0,02\right)$ e a riqueza de espécies arbóreas $\left(\beta=-11,30, r^{2}=0,24, p=0,03\right)$.

Em nosso estudo, as espécies que mais se destacaram anteriormente a capina manual (somando as abundâncias das 20 parcelas) foram: Parapiptadenia rigida $(\mathrm{N}=248)$ e Cordia trichotoma $(\mathrm{N}=104)$, Serjania glabrata $(\mathrm{N}=64)$, e Citrus limon $(\mathrm{N}=62)$. Após a remoção do capim-colonião, as espécies que mais se destacaram no tratamento com a herbácea removida foram: $P$. rigida $(\mathrm{N}=150)$, C. trichotoma $(\mathrm{N}=87)$, C. limon (74) e Mascagnia divaricata $(\mathrm{N}=59)$. Já para o bloco de controle, $P$. rigida $(\mathrm{N}=124)$ e C. trichotoma $(\mathrm{N}=70)$ foram as mais abundantes.

\section{Discussão}

A correlação negativa prévia entre cobertura herbácea (gramíneas) e abundância e riqueza de espécies é citada também por outros autores (POSADA; AIDE; CAVELIER, 2000; DUNCAN; CHAPMAN, 2003; VANDENBERGHE et al., 2006; CAMPANELLO et al., 2007; VIDRA; SHEAR; STUCKY, 2007), que sugerem que, após a remoção de parte da vegetação, as taxas de germinação e sobrevivência tendem a aumentar, já que há diminuição da competição com outras plantas e provavelmente mudanças nos parâmetros físicos ambientais, como luz que chega ao solo e microclima.

Ao contrário do esperado e do que é citado na literatura (SOUZA; BATISTA, 2004), em nosso estudo não foi encontrada uma correlação entre a $\mathrm{AD}$ e a $\mathrm{CH}$ no sub-bosque (anteriormente à capina manual - fevereiro de 2008). O que pode ter ocasionado tal fato é a época em que foram tiradas as fotos de dossel (verão), pois nessa época as árvores plantadas estão com copas plenas e a $\mathrm{CH}$ possivelmente decresce, o que não acontece no inverno (estação decídua), estação na qual as árvores perdem suas folhas e ocorre o pico de $\mathrm{AD}$ na área, e assim, com maior incremento de luz, a gramínea tem chance de permanência local aumentada.

Cabe considerar a correlação negativa entre $\mathrm{CH}$ e abundância total de indivíduos, a riqueza total de espécies e a abundância de indivíduos de espécies arbóreas, bem como as correlações negativas entre $\mathrm{AD}$ com a riqueza total de espécies, e com a abundância e riqueza de espécies arbóreas. Esses fenômenos vão ao encontro do que Barbosa (2006) propôs, o qual cita que a estrutura do reflorestamento é uma barreira tão importante para a colonização do sub-bosque quanto a distância de remanescentes florestais. Assim, mesmo o Projeto Madeira estando adjacente a um fragmento de mata em bom estado de conservação, pela presença de $P$. maximum no subbosque (favorecida pelo espaçamento amplo) e pela falta de atratividade de dispersores pelas árvores plantadas, a área apresenta sinais característicos de estágios iniciais da sucessão, com presença de poucos indivíduos arbóreos regenerantes no sub-bosque, alta densidade de gramíneas, grande quantidade de lianas, dossel aberto e interrompido por freqüentes clareiras.

Dentre as espécies que se destacaram em nosso estudo, anteriormente à capina manual, Parapiptadenia rigida e Cordia trichotoma tiveram alta abundância por terem sido plantadas no reflorestamento; Serjania glabrata é uma espécie de liana que, além de ser anemocórica, pode se beneficiar da presença do capim-colonião para usá-lo como suporte; Citrus limon é uma espécie exótica que possivelmente se favorece da presença do capim-colonião para colonizar a área. Após a remoção do capim-colonião, as espécies que mais se destacaram no bloco com a herbácea removida foram: $P$. rigida; $C$. trichotoma (que teve sua abundância mais que dobrada, passando de 39 para 87 indivíduos); resultado semelhante ocorreu para 
C. limon (inicialmente com 46 indivíduos e, após a capina, com 74), Mascagnia divaricata (antes da capina com 30 indivíduos e depois com 59) e Macfadyena unguis-cati(no início com 18 indivíduos e após a capina manual com 44). Já no tratamento controle, P. rigida e C. trichotoma foram as mais abundantes, embora não apresentaram modificações tão relevantes em suas abundâncias como aconteceu para as espécies citadas anteriormente no tratamento de capina manual.

Todas as espécies citadas no parágrafo anterior são espécies que precisam de luz nas fases iniciais do seu ciclo vital, e assim podem se beneficiar do alto grau de $\mathrm{AD}$ da área. Além disso, aquelas que foram mais abundantes no tratamento de capina manual podem ter-se favorecido da interação entre a remoção de herbácea e o grau de $\mathrm{AD}$, e germinaram com o aumento da quantidade de luz ou, ainda, cresceram e foram incluídas no estudo a partir do critério proposto (altura $10 \mathrm{~cm}$ ).

É importante salientar ainda o ingresso de espécies nas parcelas de vegetação removida e que não foram encontradas nas parcelas com a presença de capim-colonião, tais como: Cordia ecalyculata, Cupania vernalis e Schinus terebinthifolia. Entretanto, Trichilia claussenii, uma morfoespécie de Lauraceae e uma morfo-espécie de Myrtaceae, espécies caracteristicamente de estágios sucessionais mais avançados ingressaram apenas nas parcelas com a presença de capim-colonião. Assim, condições microclimáticas possivelmente alteradas pela capina manual podem ter favorecido espécies de estágios sucessionais mais iniciais e terem prejudicado a regeneração de espécies de estágios sucessionais mais avançados, como constatado por Zimmerman, Pascarella, Aide (2000), Ganade e Brown (2002), Hooper, Condit e Legendre (2002), Vandenberghe et al. (2006) e Campanello et al. (2007).

A análise dos resultados sugere que não há um efeito negativo da capina sobre a estrutura da regeneração em curto prazo (90 dias), pelo mesmo não implicar na morte acidental de indivíduos regenerantes. Ao contrário, após um tempo maior de remoção vegetal, os parâmetros de riqueza e abundância de espécies tendem a aumentar, como observado por Holl et al. (2000) e Zimmerman, Pascarella, Aide (2000), que após seis meses de monitoramento de áreas com vegetação removida (gramíneas), os autores descreveram que a riqueza e a abundância de espécies colonizadoras aumentaram, bem como a taxa de sobrevivência de espécies.

Com a visualização de plantas de menor porte, a mortalidade imposta pela capina manual é amenizada, o que não ocorre em outros métodos de controle de gramíneas, como o uso de tratores de corte rente ao chão (SAMPAIO; HOLL; SCARIOT, 2007), que além de não eliminar completamente a cobertura de gramíneas da área e ter necessidade periódica de manutenção, implica na supressão de indivíduos regenerantes. Entretanto, o método estudado é claramente indicado para áreas que tenham uma estrutura florestal mais estabelecida e para locais que tem necessidade pontual de controle de gramíneas, já que sua aplicação é inviável em áreas muito extensas.

Para um prazo maior (acima de seis meses e menos de dez anos), no entanto, dados da literatura (HOLL et al., 2000; POSADA; AIDE; CAVELIER, 2000; ZIMMERMAN; PASCARELLA; AIDE, 2000; DUNCAN; CHAPMAN, 2003; VANDENBERGHE et al., 2006; CAMPANELLO et al., 2007; VIDRA; SHEAR; STUCKY, 2007), indicam que aumentos nas taxas de germinação e de estabelecimento de plântulas são prováveis para áreas com remoção de exóticas invasoras. Em tais áreas se faz necessária a remoção contínua das mesmas para sua eliminação local, já que as mesmas podem deixar na área invadida um banco de sementes viável e longevo (VIDRA; SHEAR; STUCKY, 2007).

\section{Conclusões}

O capim-colonião (Panicum maximum Jacq.) prejudica significativamente a instalação de 
espécies colonizadoras do sub-bosque, por terse tornado uma barreira física e competir com as espécies nativas, influenciando preferencialmente as espécies arbóreas. A abertura do dossel pode afetar negativamente a riqueza de espécies locais, e assim como a cobertura de capim-colonião pode prejudicar a regeneração de espécies da área.

Para o intervalo de tempo observado (90 dias), a capina manual de herbáceas exóticas não gera impactos negativos expressivos sobre a regeneração, uma vez que a mortalidade de plântulas é limitada. Sendo assim, esse método de controle é indicado como alternativa de manejo de áreas invadidas por $P$. maximum e que tenham uma estrutura florestal mais estabelecida como a da área estudada, pois não causa prejuízos a regeneração local. Entretanto, temse a expectativa de que com a repetida eliminação da herbácea do local e aumento do tempo de observação (acima de seis meses e menos de dez anos), haja um aumento do número de indivíduos regenerantes com concomitante exclusão da herbácea invasora.

Assim, sugere-se o estudo de outras formas de manejo da herbácea para promoção da regeneração, como remoção por diferentes técnicas e plantio de adensamento com espécies de crescimento rápido para amenização do microclima, o que possibilitaria além do sombreamento da herbácea invasora e fechamento do dossel, o recrutamento de espécies de estágio sucessional mais avançados, e plantio de indivíduos de espécies de maior atratividade para a fauna (dispersão zoocórica), para acelerar a sucessão da área.

\section{Agradecimentos}

Ao Instituto Ambiental do Paraná por permitir tal estudo, em especial, à gerente do Parque Estadual "Mata dos Godoy", Leliana Dias Casagrande. Ao CNPq (processos 313854/2009-2 e 503836/20109) e à UEL pelo apoio financeiro ao projeto. A Odair do Carmo Pavão pela ajuda em campo e nas identificações. Aos revisores e aos editores da Revista Semina Ciências Biológicas por suas sugestões.

\section{Referencias}

BARBOSA, C. E. A. A estrutura da paisagem e a diversidade de plantas em reflorestamentos. 2006. 87 f. Dissertação (Mestrado em Ciências Biológicas) Universidade Estadual de Londrina, Londrina.

CAMPANELLO, P. I.; GATTI, M. G.; ARES, A.; MONTTI, L.; GOLDSTEIN, G. Tree regeneration and microclimate in a liana and bamboo-dominated semideciduous Atlantic Forest. Forest Ecology and Management, Amsterdam, v. 252, p. 108-117, 2007.

CHAPMAN, C. A.; CHAPMAN, L. J.; ZANNE, A.; BURGESS, M. A. Does weeding promote regeneration of an indigenous tree community in felled pine plantations in Uganda? Restoration Ecology, Malden, v. 10, n. 2, p. 408-415, 2002.

DENSLOW, J. S. Tropical rainforest gaps and tree species diversity. Annual Review of Ecology and Systematics, Palo Alto, v. 18, p. 431-451, 1987.

DUNCAN, R. S.; CHAPMAN, C. A. Tree-Shrub interactions during early secondary forest succession in Uganda. Restoration Ecology, Malden, v. 11, n. 2, p. 198207, 2003.

EMPRESA BRASILEIRA DE PESQUISA AGROPECUÁRIA. Centro Nacional de Pesquisa de Solo. Sistema Brasileiro de Classificação de Solos. Rio de Janeiro, 1999.

FRAZER, G. W.; CANHAM, C. D.; LERTZMAN, K. P. Gap Light Analyzer (GLA). New York: Simon Fraser University and the Institute of Ecosystem Studies, 1999.

GANADE, G.; BROWN, V. K. Succession in old pastures of central Amazonia: role of soil fertility and plant litter. Ecology, Durham, v. 83, n. 3, p. 743-754, 2002.

HOLL, K. D.; LOIK, M. E.; LIN, E. H. V.; SAMUELS, I. A. Tropical montane forest restoration in Costa Rica: overcoming barriers to dispersal and establishment. Restoration Ecology, Malden, v. 8, n. 4, p. 339-349, 2000.

HOOPER, E.; CONDIT, R.; LEGENDRE, P. Responses of 20 native tree species to reforestation strategies for abandoned farmland in Panama. Ecological Applications, Tempe, v. 12, n. 6, p. 1626-1641, 2002. 
KISSMANN, K. G. Plantas infestantes e nocivas. 2. ed. São Paulo: Basf, 1997. t. 1.

MACK, R. N.; SIMBERLOFF, D.; LONSDALE, W. M.; EVANS, H.; CLOUT, M.; BAZZAZ, F. A. Biotic invasions: causes, epidemiology, global consequences, and control. Ecological Applications, Tempe, v. 10, p. 689-710, 2000.

MONTTI, L.; CAMPANELLO, P. I.; GATTI, M. G.; BLUNDO, C.; AUSTIN, A. T.; SALA, O. E.; GOLDSTEIN, G. Understory bamboo flowering provides a very narrow light window of opportunity for canopy-tree recruitment in a neotropical forest of Misiones, Argentina. Forest Ecology and Management, Amsterdam, v. 262, p. 1360-1369, 2011.

PARROTTA, J. A. Influence of overstory composition on understory colonization by native species in plantations on a degraded tropical site. Journal of Vegetation Science, Knivsta, v. 6, n. 5, p. 627-636, 1995.

PARROTTA, J. A.; TURNBULL, J. W.; JONES, N. Catalyzing forest regeneration on degraded tropical lands. Forest Ecology and Management, Amsterdam, v. 99, p. 1-7, 1997.

PIVELLO, V. R. Invasões biológicas no cerrado brasileiro: efeitos da introdução de espécies exóticas sobre a biodiversidade. Ecologia Info, Suécia, n. 33, 2008 .

POSADA, J. M.; AIDE, T. M.; CAVELIER, J. Cattle and weedy shrubs as restoration tools of tropical montane rainforest. Restoration Ecology, Malden, v. 8, n. 4, p. 370-379, 2000.

R FOUNDATION FOR STATISTICAL COMPUTING. $\mathrm{R}$ : A language and environment for statistical computing. Vienna, 2008.

SAMPAIO, A. B.; HOLL, K. D.; SCARIOT, A. Does restoration enhance regeneration of seasonal deciduous forests in pastures in central Brazil? Restoration Ecology, Malden, v. 15, n. 3, p. 462-471, 2007.

SILVA, S. A. F. Contribuição ao estudo do "Capim Colonião" (Panicum maximum Jacq. var. maximum). Vellozia, Rio de Janeiro, v. 6, p. 3-8, 1968.

. Contribuição ao estudo do "Capim Colonião" (Panicum maximum Jacq. var. maximum) II Considerações sobre sua dispersão e seu controle. Vellozia, Rio de Janeiro, v. 7, p. 3-21, 1969.

SOUZA, F. M.; BATISTA, J. L. F. Restoration of seasonal semideciduous forests in Brazil: influence of age and restoration design on forest structure. Forest Ecology and Management, Amsterdam, v. 191, p. 185-200, 2004.
VANDENBERGHE, C.; FRELÉCHOUX, F.; GADALLAH, F.; BUTTLER, A. Competitive effects of herbaceous vegetation on tree seedling emergence, growth and survival: does gap size matter? Journal of Vegetation Science, Knivsta, v. 17, p. 481-488, 2006.

VICENTE, R. F. O parque estadual Mata dos Godoy. In: TOREZAN, J. M. D. (Org.). Ecologia do parque estadual Mata dos Godoy, Londrina: Itedes, 2006. p. 13-18.

VIDRA, R. L.; SHEAR, T. H.; STUCKY, J. M. Effects of vegetation removal on native understory recovery in an exotic-rich urban forest. Journal of the Torrey Botanical Society, Lawrence, v. 134, n. 3, p. 410-419, 2007.

WITTENBERG, R.; COCK, M. J. W. Invasive alien species: a toolkit of best prevention and management practices. Wallingford: CAB Internation, 2001.

ZIMMERMAN, J. K.; PASCARELLA, J. B.; AIDE, T. M. Barriers to forest regeneration in an abandoned pasture in Puerto Rico. Restoration Ecology, Malden, v. 8, n. 4, p. 350-360, 2000.

Recebido em 22 de setembro de 2011 Aceito em 09 de março de 2012 
